\title{
Maternal Coping with Baby Hospitalization at a Neonatal Intensive Care Unit ${ }^{1}$
}

\author{
Fabiana Pinheiro Ramos \\ Universidade Federal do Espirito \\ Santo, Vitória-ES, Brazil
}

\author{
Sônia Regina Fiorim Enumo \\ Pontificia Universidade Católica de \\ Campinas, Campinas-SP, Brazil
}

\author{
Kely Maria Pereira de Paula \\ Universidade Federal do Espírito \\ Santo, Vitória-ES, Brazil
}

\begin{abstract}
Coping is defined by actions of self-regulation of emotions, cognitions, behaviors, and motivational orientation under stress. This study analyzed the maternal coping with hospitalization of premature and low birth weight infants at the Neonatal Intensive Care Unit (NICU), using the Motivational Theory of Coping. A questionnaire, a scale and an interview were applied to 25 mothers three times between birth and hospital discharge. The results showed that the mothers' first visit to the NICU had strong emotional impact; longer hospitalization periods were linked to the decrease in Delegation coping strategies. There was more Support Seeking after the hospital discharge. Multiparous mothers and those who had a job appeared to be more vulnerable to stress. Predominantly adaptive coping responses were identified, even among two mothers whose babies had died, including Self-Reliance strategies, which were mediated by religious beliefs.
\end{abstract}

Keywords: coping behavior, premature birth, motherhood, hospitalization

\section{Enfrentamento Materno da Hospitalização do Bebê na Unidade de Terapia Intensiva Neonatal}

\begin{abstract}
Resumo: O coping é definido por ações de autorregulação emocional, cognitiva, comportamental e motivacional sob condições de estresse. Este estudo analisou, segundo a Teoria Motivacional do Coping, o processo de enfrentamento materno da hospitalização de bebês prematuros e com baixo peso, internados em Unidade de Terapia Intensiva Neonatal (UTIN). Aplicou-se em 25 mães questionário, escala e entrevista, em três momentos, do nascimento até após a alta hospitalar. Os resultados mostraram que a primeira visita materna à UTIN teve grande impacto emocional. Um maior número de dias de internação se correlacionou com a diminuição no enfrentamento por Delegação. E, após a alta hospitalar, houve aumento na Busca de Suporte. Mães multíparas e aquelas que trabalhavam fora de casa apresentaram maior vulnerabilidade ao estresse. Houve predomínio de respostas adaptativas de coping, mesmo entre as duas mães cujos bebês morreram, com a presença de estratégias de Autoconfiança, mediadas por crenças religiosas.
\end{abstract}

Palavras-chave: enfrentamento, nascimento prematuro, maternidade, hospitalização

\section{Enfrentamiento Materno de la Hospitalización del Bebé en Unidad de Terapia Intensiva Neonatal}

\begin{abstract}
Resumen: Enfrentamiento son las acciones de autorregulación de la emoción, de la cognición, del comportamiento y de la orientación motivacional en condiciones de estrés. Este estudio analizó el proceso de enfrentamiento materno de la hospitalización de bebés prematuros y con bajo peso internados en Unidad de Terapia Intensiva Neonatal (UTIN). Fueron aplicados un cuestionario, una escala y una entrevista a 25 madres en tres momentos, del nacimiento hasta después del alta hospitalaria. Los resultados mostraron que la primera visita materna a la UTIN tuvo gran impacto emocional. Un mayor número de días de internación se correlacionó con la disminución en la Delegación. Y tras el alta, aumentó la Búsqueda de Soporte. Madres multíparas y que trabajaban fuera de casa presentaron mayor vulnerabilidad al estrés. Predominaron respuestas adaptativas de enfrentamiento, incluso entre las dos madres cuyos bebés fallecieron, con la presencia de estrategias de Autoconfianza, mediadas por creencias religiosas.
\end{abstract}

Palabras clave: enfrentamiento, nacimiento prematuro, maternidad, hospitalización

\footnotetext{
${ }^{1}$ Paper deriving from the doctoral dissertation by the first author, under the advice of the second author and co-advice of the third author, defended in the Graduate Program in Psychology at the Universidade Federal do Espírito Santo. Support: National Council of Scientific and Technological Development (CNPq, Grant \# n ${ }^{\circ}$ 485564/2006-8; 481483/2009-8; doctorate schoolarship: 142308/2009-9).

${ }^{2}$ Correspondence address:

Fabiana Pinheiro Ramos. Universidade Federal do Espírito Santo, Departamento de Psicologia, Avenida Fernando Ferrari, $n^{\circ}$ 514, Goiabeiras. CEP: 29075-910. Vitória, ES. E-mail: fabiana.ramos@ufes.br
}

The hospitalization of premature (less than 37 weeks of gestational age) and low birth weight (less than 2,500 g) infants at the Neonatal Intensive Care Unit (NICU) is a stressful event for the family, particularly for the mothers (Brandon et al., 2011; Busse, Stromgren, Thorngate, \& Thomas, 2013; Chertok, McCrone, Parker, \& Leslie, 2014; Forcada-Guex, Borghini, Pierrehumbert, Ansermet, \& Muller-Nix, 2011; Yaman \& Altay, 2015). These babies are in a biopsychosocial 
situation of risk for their development (Silveira \& Enumo, 2012; Vieira \& Linhares, 2011).

The mother's perception of hospitalization is negative, and feelings of guilt, insecurity, fear and sadness are common (Barr, 2015; Sipos et al., 2013) because of the hospital's stressful routine, the painful and invasive procedures to which her baby is subject, and a temporary absence from her home and her other children that requires the transfer of responsibility for their care to another family member (Grosik, Snyder, Cleary, Breckenridge, \& Tidwell, 2013). Thus, mothers need to share their experience and feelings with someone in this context (Coppola, Cassibba, Bosco, \& Papagna, 2013).

The stress is influenced by birth variables, by the baby's immaturity and physical fragility (Grosik et al., 2013), and by the NICU that has equipment noises, a stressful routine, and a lot of movement by health professionals and other babies' parents (Alkozei, McMahon, \& Lahav, 2014). Such factors can interfere in the formation of affective bonds within the mother-child dyad (Evans, Whittingham, \& Boyd, 2012; Forcada-Guex et al., 2011; Spinelli et al., 2016). Furthermore, mothers associate the NICU with suffering and death (Hoffenkamp et al., 2015). It means that the first visit to the NICU is experienced as a shock and with feelings of sadness and anxiety (Hoffenkamp et al., 2015; Schmidt, Sassá, Veronez, Higarashi, \& Marcon, 2012).

In this stressful context, mothers have to cope with the baby's hospitalization and with the prematurity and low birth weight (PT-LBW) condition itself. The Motivational Theory of Coping (MTC) can help to understand this process. This theory defines coping as a set of actions that regulate behavior, emotion, and motivational orientation under stress (Ramos, Enumo, \& Paula, 2015; Skinner, Edge, Altman, \& Sherwood, 2003; Skinner \& Wellborn, 1994; Skinner \& Zimmer-Gembeck, 2007). According to this motivational perspective, the coping process encompasses individual efforts to maintain, restore, or repair three basic and universal psychological needs: Relatedness, Competency and Autono$m y$. Stressful events are those that threaten or challenge one's ability to fulfil these needs.

By analysing the experiences of mothers with PT-LBW babies at NICU and at risk of developmental impairments or death, we observed: (a) threats or challenges to Relatedness, as mothers who remain at the hospital with their babies are removed (temporarily) from their family and social life, and sources of social support are not always available or directly accessible at this time or even after discharge from the hospital; (b) threats or challenges to Competence, because the mothers do not always have the resources or information necessary to effectively face the challenges encountered in the hospital context and later, at home; and (c) threats or challenges to Autonomy, because the mother cannot directly influence the course of the baby's health, and so she finds herself in a situation that limits her ability to choose and to determine events (Siqueira \& Dias, 2011; Turner, Chur-Hansen, \& Winefield, 2015).

The mother's coping strategies are predictive of maternal attachment (Evans et al., 2012), maternal well-being (Affleck \& Tennen, 1991; Hoffenkamp et al., 2015), and the child's psychosocial development (Silveira \& Enumo, 2012; Vieira \& Linhares, 2011). In health contexts, religiosity appears as a central aspect of coping and can be related to it in positive or negative ways (Bryant-Davis \& Wong, 2013; Pargament, 2011), especially when the child is at risk of death. Religious or spiritual coping strategies are associated with lesser symptoms of grief in mothers whose child died at NICU (Hawthorne, Youngblut, \& Brooten, 2016).

The MTC classifies the various ways of coping with stress into 12 categories named "coping families", which are high order categories. They are associated to the individual's perception of the event as a threat or a challenge to the self or the context. Each coping family is related to an adaptive process and to a likely positive or negative result, which refers to the medium and long-term effects that the ways of coping is likely to have on physical and mental health (Skinner et al., 2003).

The following coping families are related to the adaptive process of coordinating confidence and available social resources and to the basic need for Relatedness: Self-Reliance (a challenge to self), Support Seeking (a challenge to context), Delegation (a threat to self) and Isolation (a threat to context). The coping families related to the need for Competence and to the adaptive process of coordinating actions and contingencies in the environment are Problem Solving (a challenge to self), Information Seeking (a challenge to context), Helplessness (a threat to self) and Escape (a threat to context). Regarding the adaptive process of coordinating available preferences and options and the basic need for Autonomy, the categories are Accommodation (a challenge to self), Negotiation (a challenge to context), Submission (a threat to self) and Opposition (a threat to context). In this manner, the potentially infinite ways of coping are classified into one of these 12 coping categories (Skinner et al., 2003).

Therefore, this study aims to analyze the coping process by mothers of PT-LBW at NICU from the moment of hospital admission until hospital discharge, based on the 12 coping families proposed by Motivational Theory of Coping. We understand that there are changes in the coping process over time (hypothesis) because coping is a dynamic process. The research used a multi-level method (questionnaire, scale, and interview) to procedurally capture coping, as will be presented.

\section{Method}

\section{Participants}

Twenty-five mothers of PT-LBW admitted to the NICU of a public hospital located in the Metropolitan Region of Grande Vitória, Espírito Santo, in the Southeast of Brazil, participated in this study. This hospital is a referral centre for high-risk pregnancies and neonatal intensive care. The data were collected between January and July 2010 at the hospital, with a convenience or opportunity sample (Barbetta, 2010). The inclusion criterion was the baby's hospitalization in the NICU by PT-LBW. Previous assessments of emotional aspects, disorders or other maternal variables that could influence coping were not performed. Therefore, the exclusion cri- 
teria include only the baby's hospitalization caused by other problems, except PT-LBW. During the data collection, there were 174 other mothers with PT-LBW babies at the NICU. Hence, the sample of 25 mothers represented $12.5 \%$ of this population in that period.

\section{Instruments}

General Data Registration Protocol: aimed to characterize the sample by surveying demographic and socioeconomic data, such as age, educational level, number of children, among others.

Brazilian Economic Classification Criteria (Associação Brasileira de Empresas de Pesquisa [ABEP], 2008): estimated income using certain indicators (asset ownership and educational level, for instance) and classified the participants according to their average household income into the following classes: A1 (R\$ 14.366), A2 (R\$ 8.099), B1(R\$ 4.558), B2 ( R\$ 2.327), C1 (R\$ 1.391), C2 (R\$ 933), D (R\$ 618), and $\mathrm{E}(\mathrm{R} \$ 403)$. The classification was based on the participants' self-reported scores for the items evaluated.

Breaking the News Questionnaire (adapted from Ramos, Hoffmann, \& Regen, 1985): with open and closed questions, asking the mother to remember when she received the news about her baby's hospitalization at the NICU and to describe her emotional reactions.

Ways of Coping with Problems Scale [WCPS] (Escala Modos de Enfrentamento de Problemas) (Seidl, Tróccoli, \& Zannon, 2001), based on the Ways of Coping Checklist Scale (Folkman \& Lazarus, 1985) and validated for the Brazilian population by Seidl et al. (2001): displays a list of 45 self-response statements that refer to ways of coping with specific stressors. The statements are scored according to frequency: (1) I never do this, (2) I do this a little, (3) I do this occasionally, (4) I do this often and (5) I always do this. The scale originally calculated scores based on four major factors: (a) Problem-focused coping, with 18 items $(\alpha=0,84)$; (b) Emotion-focused coping, 15 items $(\alpha=0,81)$; (c) Religious Practice/Wishful Thinking, 7 items $(\alpha=0,74)$; and (d) Social Support Seeking, 5 items $(\alpha=0,70)$.

Protocols of semi-structured interviews: the first contained questions about the mother's knowledge about PTLBW, perceptions and feelings during the first visit to NICU, the coping with the baby's hospitalization (ways of coping, social support, for example). The second protocol is about the mother's routine with the baby after hospital discharge and her concerns and feelings. The third one is specific to mothers whose babies died, including questions about coping with the baby's death. All interviews were recorded and transcribed.

In addition to these instruments, after the first contact with the mother, the research team completed the Infant Fact Sheet to register the child's neonatal variables, such as the date of birth, weight at birth, gestational age, time of NICU hospitalization, and other data extracted directly from the infant's medical notes. In addition to the principal investigator, four psychology undergraduates participated in all phases of data collection as volunteer research assistants.

\section{Procedure}

Data collection. The mothers were approached at the hospital itself and were invited to participate in the research, as part of a broader investigation that includes a group intervention program. After the procedures were explained, the mothers were asked to sign an informed consent form in accordance with Brazilian ethical standards. After giving their consent, the mothers participated in an individual data collection session (Session 1) in which the following instruments were used in this order: General Data Registration Protocol, Brazilian Economic Classification Criteria, Breaking the News Questionnaire and Ways of Coping with Problems Scale (WCPS).

After Session 1 (S1), the mothers were invited to participate in a Mothers Group Intervention. Most of the mothers $(N=16)$ participated in the group intervention between the $1^{\text {th }}$ and $6^{\text {th }}$ day of the hospitalization at NICU; 6 mothers participated between the $9^{\text {th }}$ and $14^{\text {th }}$ day; and 3 mothers between the $20^{\text {th }}$ and $67^{\text {th }}$ day. At the end of the group intervention, the mothers participated in individual semi-scripted interviews that aimed to determine how they were coping with the infant's hospitalization (Session $2-\mathrm{S} 2$ ). When the mother returned to the hospital for a follow-up (approximately two months later), the WCPS (Seidl et al., 2001) was again applied. A new interview was conducted to examine how the mother was dealing with the baby's situation after discharge from the hospital or after death in the case of the two mothers whose babies died (Session $3-\mathrm{S} 3$ ).

Data analysis. In addition to the corrections that were made to the WCPS based on its original ways of coping, for this research, the instrument's items were reclassified into the 12 coping families proposed by Skinner et al. (2003). The lack of standardized instruments for analyzing ways of coping is an ongoing problem in the field (Aldwin, 2009; Folkman \& Moskowitz, 2004); this led to an analytical proposal that would consider functional information about the ways of coping in addition to the descriptive data. This approach examined both the use of a given coping strategy and its likely positive or negative adaptive effect in the long term. Thus, the WCPS results were examined using two forms of analysis, which allowed us to compare and complement them.

The data was subject to descriptive and inferential statistical analysis (Barbetta, 2010). The following tests were applied: (a) analysis of variance (ANOVA) to verify the existence of an association between the coping strategies and: the mother's age, the educational degree, and the socioeconomic status; (b) Student's $t$-test to verify the association between the coping strategies and: mother's religion, kind of delivery, the pregnancy risk, if the mothers were primiparous, and whether the mother worked; and (c) the Pearson correlation test to verify the association between the coping strategies 
and: the mother's gestational age, the baby's birth weight, and the days of baby's hospitalization at the time of S1. For the inferential analyses, the Statistical Package for the Social Sciences (SPSS) 17.0 (SPSS Inc., Chicago, IL, USA) was used. The interviews were analyzed according to coping families using content analysis (Bardin, 2009).

\section{Ethical Considerations}

The research project was approved by the Ethics Committees of the Centre for Health Sciences of a Federal University and the State Secretariat of Health (Protocols 211/09 and $51 / 2009$, respectively) and all participants signed an informed consent form.

\section{Results}

The results are reported in central themes using data triangulation, i.e., the comparison of data collected by mixed methods - qualitative and quantitative (Barbetta, 2010), namely: descriptions of the participating mothers and their infants; an analysis of the mother's coping upon hearing the news that her infant required hospitalization; an analysis of coping during the infant's NICU hospitalization (data collected during S1 and S2); an analysis of coping after the infant's hospital discharge (data collected during S3); an analysis of coping with the infant's death in 2 of the 25 participants (data collected during S3); and, finally, a comparative analysis of coping at the different points in time.

For the description of the results, $N$ was used for the total number of respondents (mothers), and $n$ for the number of responses in a certain category, given that a mother's response to a single research question could be classified into more than one category. Additionally, because data was collected three times, there was a loss of subjects from the first session to the last. Thus, 25 mothers participated in S1, 17 mothers participated in S2, and 15 mothers participated in S3.

The sociodemographic data of the participants $(N=25)$ are: (a) age in years $-M=27.12, S D=8.25$; (b) socioeconomic status - class $\mathrm{E}=40 \%$, class $\mathrm{D}=44 \%$ and classes B2, C1 e $\mathrm{C} 2$ grouped $=16 \%$; (c) educational degree - Primary School incomplete $=24 \%$, Primary School $=28 \%$ and High School $=48 \%$; (d) marital status - marriage/stable union $=64 \%$ and single $=36 \%$; (e) professional situation - work $=48 \%$ and no work $=52 \%$; (f) religion - Catholic $=52 \%$, Evangelic (all denominations are grouped $)=44 \%$, and no religion $=4 \%$. Concerning data of pregnancy, labor and birth: (a) number of pregnancies - primiparous $=52 \%$ and multiparous $=48 \%$; (b) type of delivery - caesarean $=56 \%$ and vaginal $=44 \%$; (c) high risk pregnancy $=52 \%$; (d) twin pregnancy $=12 \%$; (e) had other PT-LBW $=12 \%$; (f) gestational age in weeks $-M=$ 32.64, $S D=3.94$; $(\mathrm{g})$ birth weight in grams $-M=1595, S D=$ 725; (h) days of hospitalization at NICU $-M=44, S D=29$.

\section{Coping with the News}

Coping on hearing the news refers to the mother's first reactions upon finding out that her baby has been born PT-
LBW and had to be admitted to the NICU and encompasses all of the ways of coping at this time; it also includes the reactions and feelings experienced upon the first visit to the infant in the NICU. Generally, upon hearing the news, the mothers did not know anything about PT-LBW and they were informed about the newborn's condition by the doctor, after birth. The doctor's information addressed the severity of the infant's condition and the risk to the infant, the fact that the infant had been born PT-LBW, had to be admitted to the NICU, and the infant's difficulty to breathe by himself/herself.

The mothers $(N=25)$ frequently reported that upon receiving the news about their baby, they experienced negative feelings, including sadness $(n=12)$, fear $(n=9)$, concern and anxiety $(n=8)$, depression $(n=5)$ and surprise $(n=3)$. There were a few positive reports of confidence $(n=2)$ and normality $(n=1)$. The mother's words to describe their feelings ("shock", "shaken", "hit rock bottom", "crushed", "bad", "hopeless", for instance) clearly convey the powerful impact that the news had on most of the mothers; only one mother did not indicate having been impacted by the news. The same pattern of feelings was again experienced upon visiting the baby for the first time at the NICU.

The following coping families and ways of coping upon hearing the news were observed based on the mothers' reports in the interview $(N=17)$ : (a) Self-Reliance (way of coping: Emotion Regulation): verbalizations that expressed confidence that the baby would overcome the situation, despite the severity of the case; (b) Support Seeking (ways of coping: Contact Seeking, Comfort Seeking, and Social Referencing): statements about seeking somebody with whom to talk about what had occurred with the baby (preferably the husband/partner); (c) Accommodation (ways of coping: Cognitive Restructuring and Minimization): verbalizations about acceptance and minimization of the severity of the situation; (d) Information Seeking (way of coping: asking others): statements about querying the health care team about the baby's condition; and (e) Helplessness (way of coping: Confusion, Cognitive Interference): statements about being confused as a result of the shock of hearing about the infant's hospital admission.

\section{Coping with Baby Hospitalization at NICU}

The coping data during the hospitalization was analyzed using the WCPS (applied in S1, N=25) and corrected according to the instrument's four original profiles. These results were: a predominance of Religious Practices/Wishful Thinking $(M=4.06, S D=0.57)$, followed by Problem-focused coping $(M=3.91, S D=0.47)$, Social Support Seeking $(M=3.03$, $S D=0.92)$ and, finally, Emotion-focused coping $(M=2.36$, $S D=0.68)$. The importance of religious coping also appeared when the 45 items of the WCPS were analyzed individually: on this occasion, the three highest averages were: (a) item 44 - I cling to my faith to overcome this situation $(M=4.79, S D$ $=0.5)$; (b) item $8-I$ pray $(M=4.64, S D=0.81)$; and (c) item 39 - I will come out of this experience better than I entered it $(M=4.64, S D=0.7)$; i.e., two of these items are categorized as religious coping. 
When the WCPS $(N=25)$ was adjusted based on the 12 coping families of Skinner et al. (2003), the highest averages were obtained for the families of Self-Reliance and Negotiation, both with an average of $4.36(S D=0.55$ and $S D=1.22$, respectively); and Delegation $(M=4.32, S D=1.01)$. The first two coping families have a positive adaptive outcome. The lowest averages were identified in the Opposition $(M=1.75$, $S D=0.72)$, Isolation $(M=2.66, S D=1.19)$, and Submission $(M=2.88, S D=0.91)$. Mothers perceived the stressors of the infant's hospitalization as a challenge.

Statistical analysis indicated that there were no significant differences between the mothers' ways of coping assessed by WCPS $(N=25)$ and the mothers' age or educational level, indicating that the sample was uniform (ANOVA). Regarding the mothers' economic class, significant differences were found $(p$-value $\leq .05)$ when the four coping families belonging to Relatedness (Self-Reliance, Support Seeking, Delegation, and Isolation) were grouped. Thus, the highest economic classes $(\mathrm{B} 2 / \mathrm{C} 2 / \mathrm{C} 1)$ had a higher coping average linked to the need for Relatedness $(p=.0048)$ according to ANOVA. We also found significant differences $(p=.043)$ in Self-Reliance, which favored mothers who did not work outside the home compared with those who worked outside the home (Student's $t$-test). The other coping families showed no significant differences between the mothers who worked outside the home and those who did not.

Analyzing the relationships among the ways of coping, also assessed by WCPS $(N=25)$ and other sociodemographic variables, and the delivery and birth variables (Student's $t$-test), we observed significant differences in the number of pregnancies (one or more) among the mothers who used the Emotion-focused coping $(p=.011)$, Helplessness $(p=.047)$, Escape $(p=.047)$ and Opposition $(p=.043)$, and the perception of threat $(p=.046)$. In other words, the multiparous mothers had a higher average of these coping families, indicating that they focused on emotions, including Helplessness, Escape, and Opposition, and that they perceived the situation as more threatening compared with primiparous mothers. In relating these data regarding the multiparous mothers to the qualitative data from the interview (S2), we observed that one of the greatest concerns among multiparous mothers was leaving their other children to care for the infant admitted to the NICU.

When considering the relationship between the WCPS results $(N=25)$ and gestational age, birthweight, and number of days in the NICU (Pearson correlation test), we detected a negative correlation between the number of days in the NICU and the Delegation $(p=.001)$, i.e., the longer the infant remained in the NICU, the lower the Delegation score was. The difference in the use of the Delegation in relation to the length of NICU stay was consistent with the qualitative data from the interview (S3): most of the mothers indicated that living with the infant's situation over time helped them recover from the initial period of difficulty and suffering.

\section{Coping After Hospital Discharge}

To examine the coping process after hospital discharge, 15 mothers were approached for S3, approximately two months after discharge. In this topic, we will present the coping process data of 13 mothers after hospital discharge, because the babies of two mothers died. Regarding their lives and routines at that point in time, the mothers $(N=13)$ noted having to devote all of their time to the baby $(n=4)$, limiting activities as a result of this care $(n=2)$, being scared and concerned about caring for and feeding the baby $(n=4)$, still learning how to care for the baby $(n=2)$, not having problems with the baby $(n=5)$, feeling better now than they did when the baby was in the NICU $(n=4)$, and finding it very good to be with the baby $(n=2)$. The mothers' concerns about the infants centred on their medical conditions and on basic parental concerns, such as returning to work and having to leave the baby with another person.

The WCPS $(N=13)$ was used to analyze the ways of coping used after hospital discharge. We found a predominance of Problem-focused coping $(M=3.83, S D=0.32)$, followed by the Religious Practices/Wishful Thinking ( $M=$ $3.78, S D=0.70)$ and Social Support Seeking $(M=3.23, S D$ $=1.00)$, and on those that are Emotion-focused coping ( $M$ $=2.36, S D=0.82$ ). Analyzing this WCPS data using the 12 coping families system (Skinner et al., 2003), the highest averages were obtained for Negotiation $(M=4.54, S D=0.78)$, Self-Reliance $(M=4.04, S D=0.53)$ and Accommodation $(M$ $=4.02, S D=0.49$ ), all with likely positive adaptive outcomes. The lowest averages were found for Opposition ( $M=1.75$, $S D=0.76)$, Isolation $(M=2.3, S D=0.99)$ and Submission $(M=2.42, S D=1.00)$. Organizing the same data to examine the perception of threat or challenge, there was a predominance of the perception of challenge $(M=3.92, S D=0.41)$, with extensive use of ways of coping that were considered positive-adaptive. After discharge from the hospital, adaptive coping predominated; reduced fear and concern regarding the baby contributed to this change.

\section{Coping with Baby's Death}

Two participants' babies died at the NICU. The first one showed the coping categories according to the four profiles of WCPS (S3): Problem-focused coping ( $M=4.66)$, followed by Religious Practices/Wishful Thinking $(M=4.14)$, Social Support Seeking $(M=4.02)$, and Emotion-focused coping ( $M$ $=2.06)$. The analysis of the same data by the 12 coping categories showed: Self-Reliance $(M=5.00)$, Problem Solving ( $M$ = 4.71), Accommodation $(M=4.60)$, Support Seeking $(M=$ $4.28)$, and Information Seeking $(M=4.00)$, i.e. coping families with adaptive results. The data indicating adaptive coping with the infant's death (at 36 days after admission) was confirmed by this mother's follow-up interview (S3), in which she claimed to be resigned and to believe that death was the best option to end her daughter's suffering at the NICU, according to her religious beliefs.

The other mother had a twin pregnancy, but she lost the first baby after delivery and the other baby after 68 days in the 
NICU. The analysis of coping with the baby's death (S3) indicated: Problem-focused coping $(M=4.00)$, followed by $R e$ ligious Practices/Wishful Thinking $(M=3.86)$, Social Support Seeking $(M=3.20)$, and Emotion-focused coping $(M=2.87)$. According to the 12 coping categories, this data indicated: Isolation $(M=5.00)$, Negotiation $(M=5.00)$, Self-Reliance $(M=4.75)$, Accommodation $(M=4.00)$, and Information Seeking $(M=4.00)$. The results of the second WCPS evaluation showed difficulties with coping that were confirmed in the follow-up interview (S3), in which this mother described her suffering over the deaths of her two babies. Nonetheless, the mother stated in the interview that she was confident she would eventually overcome these losses.

\section{Comparative Analysis of Coping Over Time}

The comparative analysis of the two coping time-points (during the infant's hospital stay and after discharge/or ba- by's death) showed that the mothers $(N=15)$ considered the infant's NICU admission more difficult. The difference between the points in time in terms of the coping process were analyzed descriptively by comparing the results of the two WCPS applications (S1 and S3), examining the differences in the four coping profiles. There was a decrease in the average scores for the Religious Practices/Wishful Thinking; it gave way to the greater use of Problem-focused coping after hospital discharge. Additionally, there was a decrease in the average of Emotion-focused coping and an increase in Social Support Seeking.

The results of the two WCPS administrations were also compared in relation to the changes in the 12 coping families by Skinner et al. (2003). To determine whether there were significant differences in the way of coping with adversities between the first and second WCPS analyses, a paired $t$-test was performed. The analysis initially included all of the mothers who completed two WCPS evaluations $(N=15)$ (Table 1$)$.

Table 1

Comparative Data Between Two Evaluations of Ways of Coping with Problems Scale in Mothers With Babies at the Neonatal Intensive Care

$\operatorname{Unit}(N=15)$

\begin{tabular}{|c|c|c|c|c|c|c|}
\hline \multirow[b]{2}{*}{ Human Psychological Needs } & \multirow[b]{2}{*}{ Stressor perception } & \multirow[b]{2}{*}{ Coping Family } & \multicolumn{2}{|c|}{ WCPS } & \multicolumn{2}{|c|}{ T-test } \\
\hline & & & $\begin{array}{c}\mathrm{S} 1 \\
M \\
(S E)\end{array}$ & $\begin{array}{c}\mathrm{S} 3 \\
M \\
(S E)\end{array}$ & $\mathrm{t}$ & ${ }^{*} p$-value \\
\hline \multirow{4}{*}{ Relatedness } & \multirow{2}{*}{ Challenge } & Self-reliance & $\begin{array}{l}4.35 \\
(.13)\end{array}$ & $\begin{array}{l}4.16 \\
(.15)\end{array}$ & 1.264 & .227 \\
\hline & & Support seeking & $\begin{array}{l}3.88 \\
(.19)\end{array}$ & $\begin{array}{l}3.98 \\
(.20)\end{array}$ & -.538 & .599 \\
\hline & \multirow{2}{*}{ Threat } & Delegation & $\begin{array}{l}4.40 \\
(.21)\end{array}$ & $\begin{array}{l}3.50 \\
(.31)\end{array}$ & 2.946 & $.011 *$ \\
\hline & & Isolation & $\begin{array}{l}2.37 \\
(.28)\end{array}$ & $\begin{array}{l}2.40 \\
(.31)\end{array}$ & -.109 & .915 \\
\hline \multirow{4}{*}{ Competence } & \multirow{2}{*}{ Challenge } & Problem-solving & $\begin{array}{l}3.34 \\
(.22)\end{array}$ & $\begin{array}{l}3.48 \\
(.18)\end{array}$ & -.792 & .441 \\
\hline & & Information seeking & $\begin{array}{l}4.00 \\
(.34)\end{array}$ & $\begin{array}{l}3.60 \\
(.32)\end{array}$ & 1.103 & .288 \\
\hline & \multirow{2}{*}{ Threat } & Helplessness & $\begin{array}{l}2.80 \\
(.31)\end{array}$ & $\begin{array}{l}3.00 \\
(.30)\end{array}$ & -.581 & .571 \\
\hline & & Escape & $\begin{array}{l}2.76 \\
(.24)\end{array}$ & $\begin{array}{l}3.22 \\
(.21)\end{array}$ & -2.276 & $.039^{*}$ \\
\hline \multirow{4}{*}{ Autonomy } & \multirow{2}{*}{ Challenge } & Accommodation & $\begin{array}{l}3.89 \\
(.17)\end{array}$ & $\begin{array}{l}4.05 \\
(.12)\end{array}$ & -.925 & .371 \\
\hline & & Negotiation & $\begin{array}{l}4.07 \\
(.38)\end{array}$ & $\begin{array}{l}4.47 \\
(.22)\end{array}$ & -.878 & .395 \\
\hline & \multirow{2}{*}{ Threat } & Submission & $\begin{array}{l}2.82 \\
(.26)\end{array}$ & $\begin{array}{l}2.48 \\
(.25)\end{array}$ & 1.512 & .153 \\
\hline & & Opposition & $\begin{array}{l}1.84 \\
(.20)\end{array}$ & $\begin{array}{l}1.81 \\
(.20)\end{array}$ & .145 & .887 \\
\hline
\end{tabular}

Note. S1 = session 1; S3 = session 3; $M=$ average; SE = Standard Error; WCPS: Ways of Coping with Problems Scale (Seidl et al., 2001); ${ }^{*} p$ $\leq .05$ is significant according to the T-test.

The first analysis showed a significant difference in the Delegation ( $p=.011$; decrease) and Escape ( $p=.039$; increase). Later, the same analysis was performed excluding those mothers whose babies had died $(N=13)$ and, when those mothers were excluded, only the first relationship was maintained, i.e., the significant decrease in the Delegation persisted (Table 2). This data shows that both mothers whose babies died increased the scores of Escape in the second assessment of WCPS. 
Table 2

Comparative Data Between Two Evaluations of Ways of Coping with Problems Scale in Mother With Alive Babies After Hospital Dis-

charge $(N=13)$

\begin{tabular}{|c|c|c|c|c|c|c|}
\hline \multirow[b]{2}{*}{ Human Psychological Needs } & \multirow[b]{2}{*}{ Stressor perception } & \multirow[b]{2}{*}{ Coping Family } & \multicolumn{2}{|c|}{ WCPS } & \multicolumn{2}{|c|}{ T-test } \\
\hline & & & $\begin{array}{c}\mathrm{S} 1 \\
M \\
(S E)\end{array}$ & $\begin{array}{c}\mathrm{S} 3 \\
M \\
(S E)\end{array}$ & $\mathrm{t}$ & *p-value \\
\hline \multirow{4}{*}{ Relatedness } & \multirow{2}{*}{ Challenge } & Self-reliance & $\begin{array}{l}4.29 \\
(.14)\end{array}$ & $\begin{array}{l}4.04 \\
(.15)\end{array}$ & 1.441 & .175 \\
\hline & & Support seeking & $\begin{array}{l}3.80 \\
(.20)\end{array}$ & $\begin{array}{l}3.97 \\
(.23)\end{array}$ & -.921 & .375 \\
\hline & \multirow{2}{*}{ Threat } & Delegation & $\begin{array}{l}4.31 \\
(.23)\end{array}$ & $\begin{array}{l}3.62 \\
(.35)\end{array}$ & 2.213 & $.047 *$ \\
\hline & & Isolation & $\begin{array}{l}2.38 \\
(.31)\end{array}$ & $\begin{array}{l}2.31 \\
(.27)\end{array}$ & .245 & .811 \\
\hline \multirow{4}{*}{ Competence } & \multirow{2}{*}{ Challenge } & Problem-solving & $\begin{array}{l}3.14 \\
(.20)\end{array}$ & $\begin{array}{l}3.39 \\
(.18)\end{array}$ & -1.657 & .123 \\
\hline & & Information seeking & $\begin{array}{l}3.85 \\
(.37)\end{array}$ & $\begin{array}{l}3.54 \\
(.37)\end{array}$ & .743 & .472 \\
\hline & \multirow{2}{*}{ Threat } & Helplessness & $\begin{array}{l}2.65 \\
(.33)\end{array}$ & $\begin{array}{l}3.08 \\
(.33)\end{array}$ & -1.184 & .259 \\
\hline & & Escape & $\begin{array}{l}2.72 \\
(.28)\end{array}$ & $\begin{array}{l}3.19 \\
(.24)\end{array}$ & -2.052 & .063 \\
\hline \multirow{4}{*}{ Autonomy } & \multirow{2}{*}{ Challenge } & Accommodation & $\begin{array}{l}3.75 \\
(.16)\end{array}$ & $\begin{array}{l}4.02 \\
(.13)\end{array}$ & -1.477 & .165 \\
\hline & & Negotiation & $\begin{array}{l}3.92 \\
(.43)\end{array}$ & $\begin{array}{l}4.54 \\
(.22)\end{array}$ & -1.262 & .231 \\
\hline & \multirow{2}{*}{ Threat } & Submission & $\begin{array}{l}2.71 \\
(.29)\end{array}$ & $\begin{array}{l}2.42 \\
(.28)\end{array}$ & 1.187 & .258 \\
\hline & & Opposition & $\begin{array}{l}1.89 \\
(.23)\end{array}$ & $\begin{array}{l}1.75 \\
(.21)\end{array}$ & .626 & .543 \\
\hline
\end{tabular}

Note. S1 = session 1; S3 = session 3; $M=$ average; SE = Standard Error; WCPS: Ways of Coping with Problems Scale (Seidl et al., 2001); * $p$ $\leq .05$ is significant according to T-test.

\section{Discussion}

This study analyzed the maternal coping process with babies' hospitalization at NICU by Motivational Theory of Coping (Ramos et al., 2015; Skinner et al., 2003; Skinner \& Wellborn, 1994; Skinner \& Zimmer-Gembeck, 2007). The results collected from 25 mothers showed that a previous lack of knowledge about PT-LBW was predominant among these mothers, confirming that novelty was a factor in this context. Both novelty and unpredictability (caused by the severity of the babies' conditions) contribute to the perception of an environment as stressful (Chertok et al., 2014; Grosik et al., 2013). The mothers' lack of knowledge about the NICU conditions caused them to feel "shock" upon hearing the news and upon their first visit to the NICU, as showed by Schmidt et al. (2012). Thus, it seems important to accompany the parents on the first NICU visit (the so-called "monitored visit") to provide emotional support and information on the equipment and routine surrounding the newborn (Siqueira \& Dias, 2011). Monitored visits did not exist at this hospital during this study.

At this first moment, the mother's predominant feelings were sadness, fear and anxiety, as showed by studies in this area (Barr, 2015; Sipos et al., 2013). Such feelings are associated with Helplessness. Nonetheless, positive-adaptive ways of coping also occurred, such as Self-Reliance, Accommodation, Support Seeking, and Information Seeking, despite the negative emotions experienced upon the first contact with the stressor. Concerning Support Seeking, the husband/partner was the preferred person to talk about the baby's situation, as noticed by Coppola et al. (2013).

The passage of time, living with the stressor, and a greater understanding of the situation seemed to facilitate the coping process for most of the mothers; nonetheless, they continue to view the situation as a challenge. The decrease of Delegation as the hospital stay increased is indicative of this process. Furthermore, participation in the group intervention should be a factor to contribute to changes in the coping strategies of these mothers, as showed by literature (Chertok et al., 2014; Turner et al., 2015). This condition could have altered the mother's answers in the first interview (S2), but these situations were not analyzed in this study.

To cope with the infant's hospitalization, faith and trust in God seem essential for helping these women to bear the suffering they experience as a result of having an infant at 
the NICU, a positive religious coping form (Bryant-Davis \& Wong, 2013). Among the mothers' coping, the Self-Reliance mediated by religious beliefs stands out. The use of such strategies allowed them to remain optimistic and continue to hope for the baby's recovery despite adversities. Religiosity was a resource for emotion regulation in relation to the stressors, as was positive self-talk (Pargament, 2011).

Regarding the mothers' characteristics, we found that multiparous mothers and those who worked outside the home were more vulnerable to the stressor because they presented more ways of coping that had a likely negative outcome. We observed that one of the greatest concerns among multiparous mothers was leaving their other children, to care for the infant admitted to the NICU. This concern can explain why the multiparous mothers' coping placed a greater emphasis on emotions and why they perceived the situation as more threatening compared to the primiparous mothers, who only had to focus on the infant admitted to the NICU.

In the context of an infant's NICU admission, work can pose a great concern for mothers by making the management of available resources and the use of emotional and behavioral regulation more difficult. The accumulation of tasks and concerns may increase the likelihood that the stressor is perceived as a threat (Grosik et al., 2013); thus, interventions in this context should take into account the increased vulnerability of mothers with these characteristics. We did not find other studies about coping with babies' hospitalization at NICU that confirm those differences in coping according to the mother's profile (multiparous and/or working).

The analysis of the different points in time provided a view of how the mothers' ways of coping changed over time. After discharge from the hospital, the use of Religious coping diminished and the Problem-focused coping increased, possibly because the mothers may have developed more effective ways of coping with the baby's problems. After discharge, there was also an increase in Support Seeking because, once she had returned home and was near family, the mother had more access to support. The predominance of Problem-focused coping may indicate that the mothers were concentrating on ways to resolve situations that persist day after day with the baby at home, although religious support remains an important coping resource.

These findings show that the mothers were exposed to a risk situation because the stressor that they faced (the baby's admission to the NICU and the PT-LBW condition itself) was unknown and unpredictable and, in the case of death, irreversible; the participants largely adapted positively to the situation, especially in the use of Self-Reliance. As a result, the consequences of the mothers' mental and physical coping health tended to be positive in the long term. Nonetheless, it is important to consider that the present study used a convenience sample; thus, our results have limited generalization level. In addition, our study had some limitations, including the small sample size and sample loss from the first to the last data collection session.

This study identified and analyzed the mother's ways of coping with the stressor of a baby's NICU admission at different moments during the hospitalization until the hospi- tal discharge, with a multi-methodological perspective. The analysis of data collected from one theoretical perspective (WCPS) under the Motivational Theory of Coping (Skinner et al., 2003) is a methodological contribution of this study. Thus, we can show the feasibility of this coping system classification of MTC. This system allows us to make inferences about the consequences of coping in the long term (adaptive or maladaptive), different from the original profile of the WCPS that only offers limited coping categories, in a descriptive way (Folkman \& Lazarus, 1985).

The study of the ways of coping with adverse situations is essential to understand the variables involved in overcoming adversity and constructing healthy development interventions, which most participating mothers did, including those whose babies died. Therefore, future investigations might elucidate the psychological mechanisms involved in overcoming stressful events, such as an infant's admission to the NICU, and their connection with the mother's ways of coping with the stressors adopted at different times in this process.

\section{References}

Affleck, G., \& Tennen, H. (1991). Appraisal and coping predictors of mother and child outcomes after newborn intensive care. Journal of Social and Clinical Psychology, 10(4), 424-447. doi:10.1521/jscp.1991.10.4.424

Aldwin, C. M. (2009). Stress, coping and development: An integrative perspective (2nd ed.). New York, NY: Guilford.

Alkozei, A., McMahon, E., \& Lahav, A. (2014). Stress levels and depressive symptoms in NICU mothers in the early postpartum period. The Journal of Maternal-Fetal \& Neonatal Medicine, 27(17), 1738-1743. doi:10.3109/1476705 8.2014 .942626

Associação Brasileira de Empresas de Pesquisa. (2008). Critério de Classificação Econômica Brasil [Brazilian Economic Classification Criteria]. Retrieved from http:// www.abep.org/criterio-brasil

Barbetta, P. A. (2010). Estatística aplicada às Ciências Sociais [Statistics applied to the social sciences] (7a ed.). Florianópolis, SC: Editora da UFSC.

Bardin, L. (2009). Análise de conteúdo [Content analysis] (L. A. Reto \& A. Pinheiro, Trans.). Lisboa, Portugal: Edições 70.

Barr, P. (2015). Guilt, shame and fear of death predict neonatal intensive care unit-related parental distress. Journal of Reproductive and Infant Psychology, 33(4), 402-413. doi: 10.1080/02646838.2015.1043624

Brandon, D. H., Tully, K. P., Silva, S. G., Malcolm, W. F., Murtha, A. P., Turner, B. S., \& Holditch-Davis, D. (2011). Emotional responses of mothers of late- preterm and term infants. Journal of Obstetric, Gynecologic, \& Neonatal Nursing, 40(6), 719-731. doi:10.1111/j.15526909.2011.01290.x 
Bryant-Davis, T., \& Wong, E. C. (2013). Faith to move mountains: Religious coping, spirituality and interpersonal trauma recovery. American Psychologist, 68(8), 675-684. doi:10.1037/a0034380

Busse, M., Stromgren, K., Thorngate, L., \& Thomas, K. A. (2013). Parents' responses to stress in the neonatal intensive care unit. Critical Care Nurse, 33(4), 52-60. doi:10.4037/cen2013715

Chertok, I. R., McCrone, S., Parker, D., \& Leslie, N. (2014). Review of interventions to reduce stress among mothers of infants in the NICU. Advances in Neonatal Care, 14(1), 30-37. doi:10.1097/ANC.0000000000000044

Coppola, G., Cassibba, R., Bosco, A., \& Papagna, S. (2013). In search of social support in the NICU: Features, benefits and antecedents of parents' tendency to share with others the premature birth of their baby. The Journal of Maternal-Fetal \& Neonatal Medicine, 26(17), 1737-1741. doi:1 $0.3109 / 14767058.2013 .798281$

Evans, T., Whittingham, K., \& Boyd, R. (2012). What helps the mother of a preterm infant become securely attached, responsive and well-adjusted? Infant Behavior and Development, 35(1), 1-11. doi:10.1016/j.infbeh.2011.10.002

Folkman, S., \& Lazarus, R. S. (1985). If it changes it must be a process: Study of emotion and coping during three stages of a college examination. Journal of Personality and Social Psychology, 48(1), 150-170. doi:10.1037/0022-3514.48.1.150

Folkman, S., \& Moskowitz, J. T. (2004). Coping: Pitfalls and promise. Annual Review Psychology, 55, 745-774. doi:10.1146/annurev.psych.55.090902.141456

Forcada-Guex, M., Borghini, A., Pierrehumbert, B., Ansermet, F., \& Muller-Nix, C. (2011). Prematurity, maternal posttraumatic stress and consequences of mother-infant relationship. Early Human Development, 87(1), 21-26. doi:10.1016/j.earlhumdev.2010.09.006

Grosik, C., Snyder, D., Cleary, G. M., Breckenridge, D. M., \& Tidwell, B. (2013). Identification of internal and external stressors in parents of newborn in intensive care. The Permanente Journal, 17(3), 36-41. doi:10.7812/TPP/12-105

Hoffenkamp, H. N., Braeken, J., Hall, R. A. S., Tooten, A., Vingerhoets, J. J. M., \& van Bakel, H. J. A. (2015). Parenting in complex conditions: Does preterm birth provide a context for the development of less optimal parental behavior? Journal of Pediatric Psychology, 40(6), 559-571. doi:10.1093/jpepsy/jsv007

Hawthorne, D. M., Youngblut, J. M., \& Brooten, D. (2016). Parent spirituality, grief, and mental health at 1 and 3 months after their infant's/child's death in an Intensive Care Unit. Journal of Pediatric Nursing, 31(1), 73-80. doi:10.1016/j.pedn.2015.07.008

Pargament, K. I. (2011). Religion and coping: The current state of knowledge. In S. Folkman (Ed.), Oxford handbook of stress, health, and coping (pp. 269-288). New York, NY: Oxford University Press.
Ramos, F. P., Enumo, S. R. F., \& Paula, K. M. P. (2015). Teoria Motivacional do Coping: Uma proposta desenvolvimentista de análise do enfrentamento do estresse [Motivational Theory of Coping: A developmental proposal for the analysis of coping with stress]. Estudos de Psicologia (Campinas), 32(2), 269-279. doi:10.1590/0103166X2015000200011

Ramos, T. C. L., Hoffmann, V. M. B., \& Regen, M. (1985). As dificuldades em transmitir a notícia: Pesquisa junto a pais de pacientes portadores de Síndrome de Down [The difficulties in relaying the news: Survey of parents of Down syndrome patients]. Revista Brasileira de Deficiência Mental, 18(1), 47-69.

Schmidt, K. T., Sassá, A. H., Veronez, M., Higarashi, I. H., \& Marcon, S. S. (2012). A primeira visita ao filho internado na unidade de terapia intensiva neonatal: Percepção dos pais [The first visit to a child in the neonatal intensive care unit: Parent perception]. Escola Anna Nery, 16(1), 73-81. doi:10.1590/S1414-81452012000100010

Seidl, E. M. F., Tróccoli, B. T., \& Zannon, C. M. L. C. (2001). Análise fatorial de uma medida de estratégias de enfrentamento [Factor analysis of a measure of ways of coping]. Psicologia: Teoria e Pesquisa, 17(3), 225-234. doi:10.1590/S0102-37722001000300004

Silveira, K. A., \& Enumo, S. R. F. (2012). Biopsychosocial risks to development in preterm and low birth weight. Paidéia (Ribeirão Preto), 22(53), 335-345. doi:10.1590/1982-43272253201305

Sipos, L., Pers, B. M., Kalmár, M., Tóth, I., Krishna, S., Jensen, M. H., \& Semsey, S. (2013). Comparative network analysis of preterm vs. full-term infant-mother interactions. PloS One, 8(6), e67183. doi:10.1371/journal. pone. 0067183

Siqueira, M. B. C., \& Dias, M. A. B. (2011). A percepção materna sobre vivência e aprendizado de cuidado de um bebê prematuro [Mother's perception of living and learning to care a preterm baby]. Epidemiologia $e$ Serviços de Saúde, 20(1), 27-36. doi:10.5123/S167949742011000100004

Skinner, E. A., Edge, K., Altman, J., \& Sherwood, H. (2003). Searching for the structure of coping: A review and critique of category systems for classifying ways of coping. Psychological Bulletin, 129(2), 216-269. doi:10.1037/00332909.129.2.216

Skinner, E. A., \& Wellborn, J. G. (1994). Coping during childhood and adolescence: A motivational perspective. In D. L. Featherman, R. M. Lerner, \& M. Perlmutter (Eds.), Life-span development and behavior (Vol. 12, pp. 91133). Hillsdale, NJ: Lawrence Erlbaum.

Skinner, E. A., \& Zimmer-Gembeck, M. J. (2007). The development of coping. Annual Review of Psychology, 58, 119144 doi:10.1146/annurev.psych.58.110405.085705 
Spinelli, M., Frigerio, A., Montali, L., Fasolo, M., Spada, M. S., \& Mangili, G. (2016). 'I still have difficulties feeling like a mother': The transition to motherhood of preterm infants mothers. Psychology \& Health, 31(2), 184-204. do i: $10.1080 / 08870446.2015 .1088015$

Turner, M., Chur-Hansen, A., \& Winefield, H. (2015). Mothers' experiences of the NICU and a NICU support group programme. Journal of Reproductive and Infant Psychology, 33(2), 165-179. doi:10.1080/02646838.2014.998184

Vieira, M. E. B., \& Linhares, M. B. M. (2011). Desenvolvimento e qualidade de vida em crianças nascidas pré-termo em idades pré-escolar e escolar [Developmental outcomes and quality of life in children born preterm at preschooland school-age]. Jornal de Pediatria, 87(4), 282-291. doi:10.2223/JPED.2096

Yaman, S., \& Altay, N. (2015). Posttraumatic stress and experiences of parents with a newborn in the neonatal intensive care unit. Journal of Reproductive and Infant Psychology, 33(2), 140-152. doi:10.1080/02646838.2014.990872

Fabiana Pinheiro Ramos is a Professor of the Department of Psychology at the Universidade Federal do Espírito Santo.

Sonia Regina Fiorim Enumo is an Emeritus Professor at the Universidade Federal do Espírito Santo, and a Professor in the Graduate Program in Psychology, and the Graduate Program in Health Sciences at the Pontifícia Universidade Católica de Campinas.

Kely Maria Pereira de Paula is a Professor of the Departament of Social Psychology and Development at the Universidade Federal do Espírito Santo.

Received: Feb. 12, 2016

1st Revision: Sep. 2, 2016

Approved: Sep. 16, 2016

How to cite this article:

Ramos, F. P., Enumo, S. R. F., \& Paula, K. M. P. (2017). Maternal coping with baby hospitalization at a Neonatal Intensive Care Unit. Paidéia (Ribeirão Preto), 27(67), 10-19. doi: 10.1590/1982-43272767201702 